Article

\title{
Study of POSS on the Properties of Novel Inorganic Dental Composite Resin
}

\author{
Jiahui Wang ${ }^{1}$, Yizhi Liu ${ }^{2, *}$, Jianxin Yu ${ }^{3}$, Yi Sun ${ }^{2}$ and Weili Xie ${ }^{4}$ \\ 1 College of materials, Shanghai Dianji University, Shanghai 200000, China; wangjh@sdju.edu.cn \\ 2 Department of Astronautic Science and Mechanics, Harbin Institute of Technology, Harbin 150000, China; \\ sunyi@hit.edu.cn \\ 3 School of Materials Science and Engineering, Harbin Institute of Technology, Harbin 150000, China; \\ yujianxin03242@163.com \\ 4 Department of Stomatology, Harbin Medical University, Harbin 150000, China; xw1811@126.com \\ * Correspondence: liuyizhi@hit.edu.cn
}

Received: 16 January 2020; Accepted: 18 February 2020; Published: 20 February 2020

\begin{abstract}
Various amounts of methacryl polyhedral oligomeric silsesquioxane (POSS) were explored to be incorporated into novel nano $\mathrm{SiO}_{2}$ dental resin composites using light curing method. The scanning electron microscopy (SEM), optical microscopy, fourier transform infrared spectroscopy (FTIR), nanoindentation, nanoscratch and three-point flexure tests were performed. The volumetric shrinkage and mechanical properties such as hardness, elastic modulus, resistance, flexural strength and fracture energy were analyzed. With the additions of POSS, the volume shrinkage decreased and the mechanical properties initially increased. The effects of POSS on these properties were studied to provide a reference for clinically selecting a composite resin with excellent properties.
\end{abstract}

Keywords: dental composite resin; POSS; shrinkage; hardness; strength

\section{Introduction}

Currently, the composite resin is the most important repairing material for tooth defects. Because of its many advantages such as color, strong plasticity, resistance to dissolution, easy polishing, simple operation, and close to the coefficient of thermal expansion, it is mainly used for fillings and restoration of dental caries and plays a pivotal role in dental restoration [1-3]. However, some of its shortcomings such as poor strength, bad abrasion resistance, and large polymerization shrinkage are also exposed as the service time increases. The application of new nanofillers in dental resins has been widely studied to improve the mechanical and anti-caries properties [4-6].

Polyhedral oligomeric silsesquioxane (POSS) is an organic-inorganic hybrid nanomaterial $[7,8]$. The composite resin with POSS as a filler has good biocompatibility and mechanical properties [9-14]. POSS is represented by the unique formula $\left(\mathrm{RSiO}_{3 / 2}\right)_{\mathrm{n}}$, where $\mathrm{n}$ is the number of the silicon atoms of the cage (1-3 nm in size) surrounded by organic corner groups $(\mathrm{R})$. Due to its inorganic $\mathrm{Si}-\mathrm{O}$ core cage structure and optional organic group chains, POSS can enhance matrix properties, such as mechanical strength [15-17], thermal stability [18-20] and oxidation resistance [21-23], and it can maintain good compatibility with the matrix in micro or nano scales. Meanwhile, POSS used in dental restoration can significantly improve the matrix on marginal adaptation [24,25] and ensure good biocompatibility and comfort level $[4,26]$, which can greatly reduce the risk of micro effusion and secondary caries.

Ogliari et al. [27] simulated the shelf life to evaluate the stability of initiation systems on acidic photopolymerizable dental material through an experimental self-adhering flowable composite resin with bisphenol-A glycidyl methacrylate (Bis-GMA), tri-ethylene glycol dimethacrylate (TEGDMA), acidic monomer (GDMA-P), and inorganic fillers. Patnaik et al. [28] fabricated the resin matrix 
consisting of Bis-GMA, TEGDMA, camphorquinone (CQ) and ethyl 4 dimethyl amino benzoate $(E D M A B)$, and evaluated mechanical and thermal properties and polymerization shrinkage with maximum conversion. Hao Fong et al. [29] chose methacryl POSS to incorporate into Bis-GMA for prepared novel dental restorative composites. The results showed that only a small percentage of methacryl POSS substitution of Bis-GMA in the resin systems could improve the mechanical properties of the composite. In our previous works [30,31], different contents of methacryl POSS were added into dental composite resins and BG (barium oxide glass powder) matrix dental composite resins, respectively, and some properties including polymerization shrinkage and mechanical behavior were evaluated.

In this work, various amounts of methacryl POSS were explored to be incorporated into novel nano $\mathrm{SiO}_{2}$ matrix dental resin composites using light curing method. The scanning electron microscopy (SEM), optical microscopy, fourier transform infrared spectroscopy (FTIR), nanoindentation, nanoscratch and three-point flexure tests were performed, and the effects of the contents of POSS on the volumetric shrinkage, hardness, elastic modulus, resistance flexural strength and fracture energy were studied.

\section{Experimental}

Bis-GMA (Bisphenol A glycerolate dimethacrylate) and TEGDMA (Tri(ethylenglycol) dimethacrylate, $98 \%$ ) were purchased from Aldrich Chemical Co., Shanghai, China. The commonly used visible light photo-initiator CQ (camphorquinone, 97\%) and co-initiator (2-(dimethylamino) ethylmethacrylate, DMAEMA, 98\%) were selected for this research and purchased from Aldrich Chemical Co., Shanghai, China. The inorganic filler used in this study was surface modified KH-550 nano $\mathrm{SiO}_{2}$ with an average particle size of $30 \mathrm{~nm}$, purchased from Deco Dokin Co. Shanghai, China. Surface modified KH-550 nano $\mathrm{SiO}_{2}$ is a white powder that mixes better with the matrix and provides better mechanical properties to the matrix compared with dental resin matrix without inorganic filler. All of the above materials can be used as a dental resin matrix. Methacryl POSS was obtained from Hybrid Plastics (Fountain Valley, Hattiesburg, CA, USA, Figure 1). The proportions of POSS hybrid inorganic dental composite resin and organic resin matrix were listed in Tables 1 and 2.
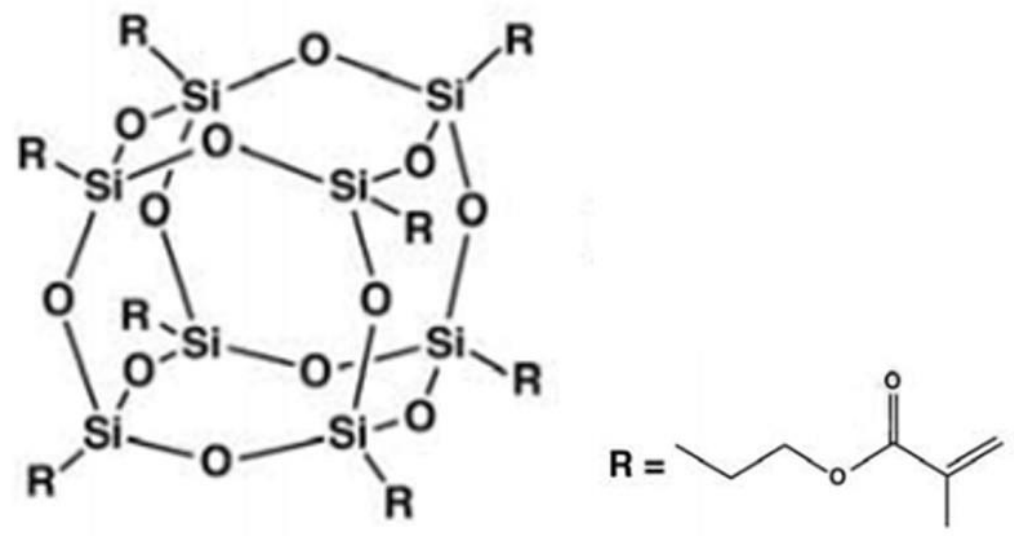

Figure 1. The molecule structure of methacryl polyhedral oligomeric silsesquioxane (POSS).

Table 1. The proportion of POSS hybrid inorganic dental composite resin.

\begin{tabular}{cccc}
\hline Composite Code & Dental Resin Matrix & POSS \\
\hline & Organic Resin Matrix Wt\% & Nano SiO $_{2}$ & \\
\hline P00 & 40 & 60 & 0 \\
P02 & 38 & 60 & 2 \\
P05 & 35 & 60 & 5 \\
P10 & 30 & 60 & 10 \\
\hline
\end{tabular}


Table 2. The proportion of organic resin matrix. Bis-GMA: bisphenol-A glycidyl methacrylate; TEGDMA: tri-ethylene glycol dimethacrylate; CQ: camphorquinone; DMAEMA: 2-(dimethylamino) ethylmethacrylate.

\begin{tabular}{cccc}
\hline \multicolumn{4}{c}{ Organic Resin Matrix, $\mathbf{W t} \%$} \\
\hline Bis-GMA & TEGDMA & CQ & DMAEMA \\
\hline 49.5 & 49.5 & 0.5 & 0.5 \\
\hline
\end{tabular}

\subsection{Synthesis of Materials}

An organic resin matrix solution containing Bis-GMA, TEGDMA, CQ and DMAEMA was prepared by mixing in a container kept away from light. Methacryl POSS was added to the solution of neat resins. Nano $\mathrm{SiO}_{2}$ was incorporated into the organic composite solution and magnetically blended uniformly in the vacuum allowing for the escape of air bubbles for $2 \mathrm{~h}$. The mixture solution was poured into metal molds and the visible light curing method was applied. The curing time of each sample was $60 \mathrm{~s}$ at room temperature. The prepared samples were immersed in distilled water at $37^{\circ} \mathrm{C}$ for $24 \mathrm{~h}$ and were stored in configured artificial saliva at $36.5^{\circ} \mathrm{C}$ for 4 weeks. The sizes of the specimens were measured accurately and recorded immediately before testing.

\subsection{Characterization}

\subsubsection{FTIR Characterization}

Fourier transform infrared (FTIR) spectroscopy analysis was performed using the FTIR spectrometer (Avatar360, Nicolet, Madison, US). The samples involved in this part of the study were POSS and organic composite resins without inorganic filler.

\subsubsection{Morphology Characterization}

A VHX-600E digital microscope (Keyence Company, Shanghai, China) was used for optical microscopy of the nanocomposite resins with a real-time depth composition, two/three dimensional functions, and 500-5000 zoom.

The fracture morphology of the POSS dental resin composite was characterized using a field-emission scanning electron microscope (FESEM, JEOL 7600F, Osaka, Japan).

\subsubsection{Shrinkage}

The densities of uncured and cured resin specimens were measured by a pycnometer to determine polymerization shrinkage according to the Archimedes' principle.

\subsubsection{Mechanical Properties Tests}

The G200 Nano Indenter (Agilent Technologies, Santa Clara, CA, USA) was employed to study the hardness of the nanocomposite resins. The indenter used in the test was a diamond triangular pyramid Berkovich indenter (TB 20114 ISO). The maximum depth of $2000 \mathrm{~nm}$ was used on each sample. The loading speed was maintained at the same strain rate of $0.05 \mathrm{~s}^{-1}$. The data was averaged from six specimens during each test to get the most accurate results.

The G200 Nano Indenter was also used to measure the resistance of the nanocomposite by the nanoscratch testing. The indenter tip scratched on the sample with a wear load value of $200 \mathrm{mN}$. The scratch length and speed were set as $400 \mu \mathrm{m}$ and $10 \mu \mathrm{m} / \mathrm{s}$, respectively. Three independent scratch tests were carried out for each sample.

A T1-FR010TH A50 (ZWICK Materials Testing Machine, Ulm, Germany) was used to measure flexural strength by three-point flexure testing (according to ISO4049: 2000) at a crosshead speed of $0.5 \mathrm{~mm} / \mathrm{min}$. The specimens were prepared in stainless steel molds with a dimension of $2 \mathrm{~mm}$ by $2 \mathrm{~mm}$ $\times 25 \mathrm{~mm}$ in length. 
A three-point flexure test was also used to measure the fracture energy, which is the dissipative outside energy during fracture. Fracture energy can be used as the measurement of the toughness of the materials.

\section{Results and Discussion}

\subsection{FTIR Analysis}

The FTIR spectra of composite resins with different POSS additions are shown in Figure 2. The band at $1635 \mathrm{~cm}^{-1}$ was attributed to characteristic absorption peaks of $\mathrm{C}=\mathrm{C}$ bond. After the curing reaction, the methacrylate double bonds had partly changed and the peak intensity decreased. The band at $1120 \mathrm{~cm}^{-1}$ is attributed to the stretching vibration of Si-O-Si in POSS. With the increasing addition of POSS, the peak intensity increased [32].

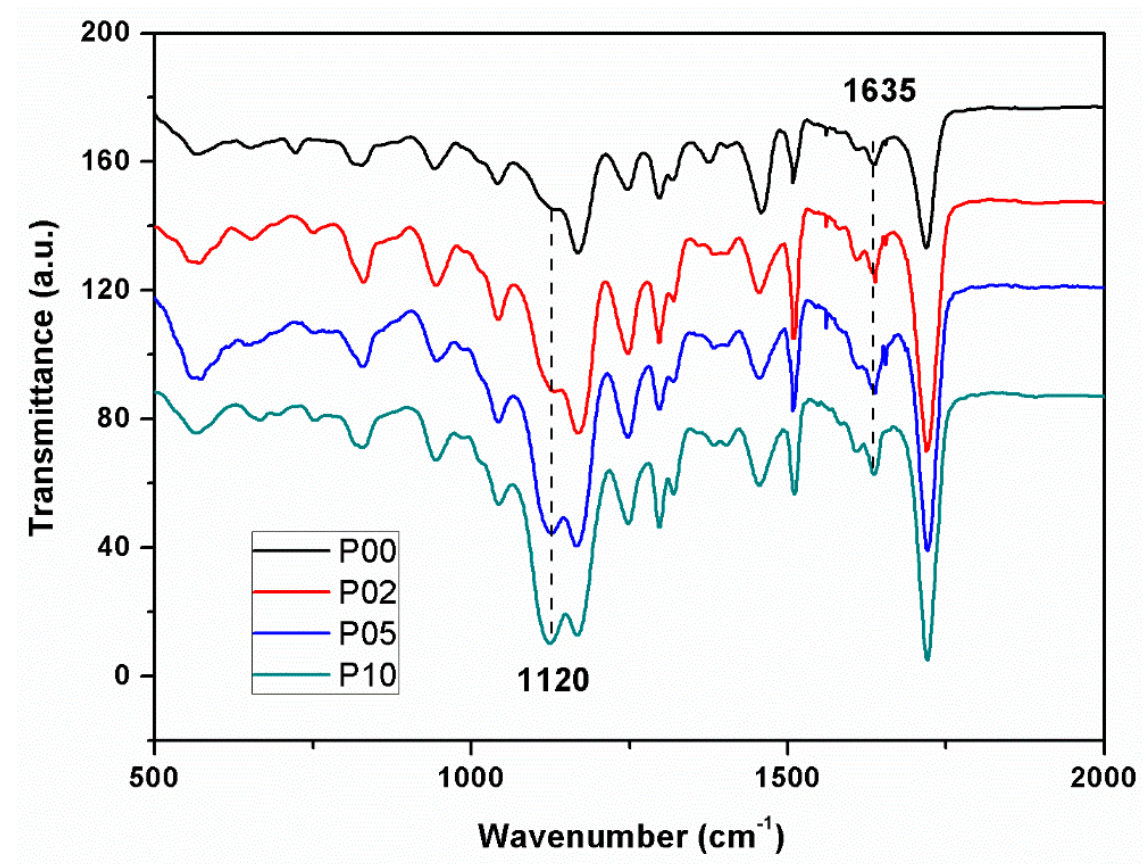

Figure 2. FTIR spectra of composite resins with different POSS additions.

\subsection{Low Volumetric Shrinkage}

The volumetric shrinkage of POSS hybrid inorganic dental composite resin was evaluated. The volumetric shrinkage value of the dental resin matrix was 3.59\%. With the increasing additions of POSS, the volume shrinkage decreased. The values were about $2.98 \%, 2.87 \%$ and $2.54 \%$ with the addition of $2 \%, 5 \%$ and $10 \%$ POSS, respectively. POSS reduced the shrinkage of resins obviously due to the limitation of free volume variation. Before curing, large chain monomers such as Bis-GMA and TEGDMA were dispersed in the matrix. After curing, the movement of chains was not limited by amount of cross-linked points and the free volume of resins changed remarkably. When the addition of POSS was incorporated in resins, due to its unique inorganic nanocage surrounded with organic groups, it can attract and even entwine monomer chains, which made monomers disperse more tightly before the reaction. The movement of chains is limited by plenty of cross-linked points. The unique nanocage structure of POSS limited the change of free volume of the resin and the volume of the nanocage of POSS did not change after the reaction.

\subsection{Mechanical Properties}

The small addition of POSS remarkably enhanced the hardness and scratch resistance of the dental resin matrix. The hardness and elastic modulus of composite resins with different POSS additions 
were shown in Figure 3. The effective penetration depth curves of neat dental resin matrix under the load and average scratch depth of composite resins with different POSS additions were shown in Figures 4 and 5, respectively. Compared with typically used fillers, a low amount of POSS can increase mechanical properties $[12,33]$. As the POSS addition increased, the nanoparticles and the resin chains attracted tightly and formed big polymer particles, which was benefit to stress transfer. The mechanical properties of the composite initially increased. When it exceeded $5 \mathrm{wt} \%$, the heterogeneous distribution and stress concentration appeared. The mechanical properties of the POSS composite resin reduced. These properties showed a similar variation trend according to the percentage of POSS, which indicates that POSS have the same influence on the composite matrix. Meanwhile, compared with the pure organic matrix and dental matrix with barium oxide glass powder $[28,29]$, the mechanical properties of matrix containing with nano $\mathrm{SiO}_{2}$ are also improved obviously.

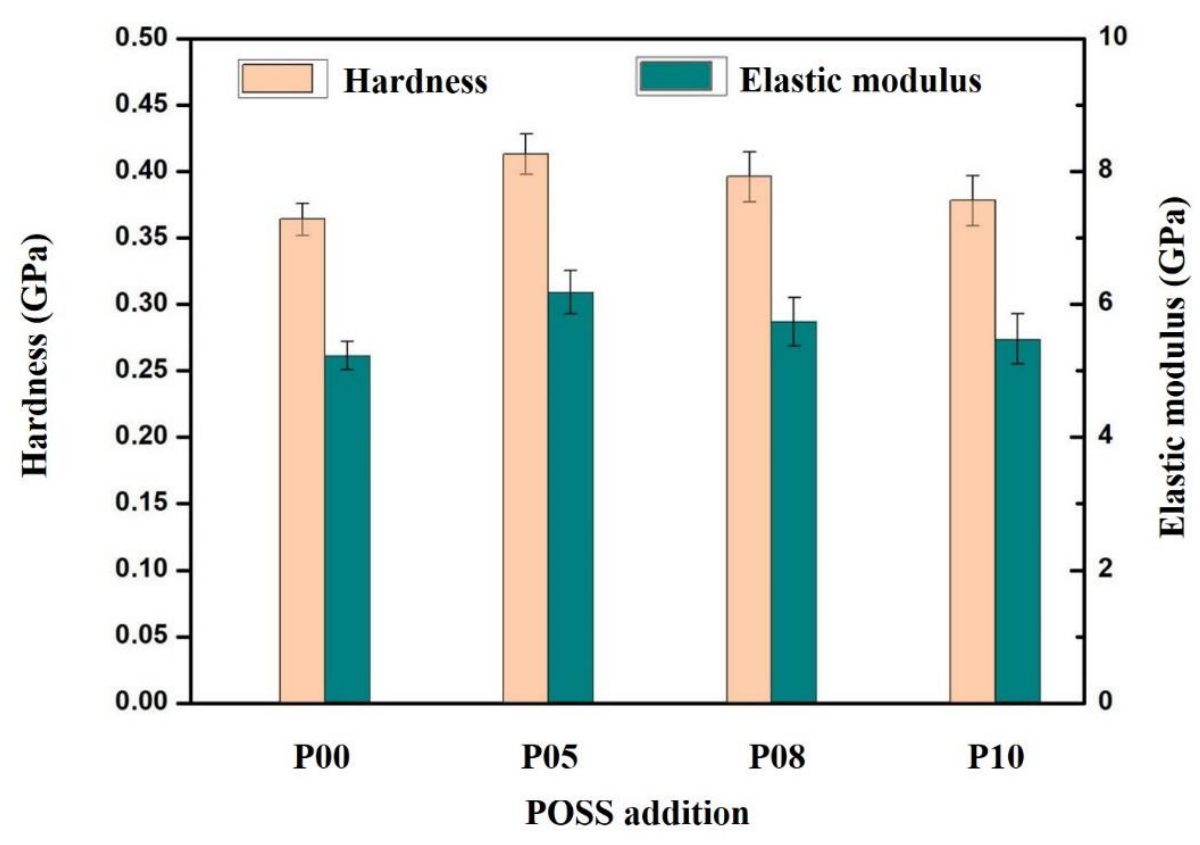

Figure 3. Hardness and elastic modulus of composite resins with different POSS additions.

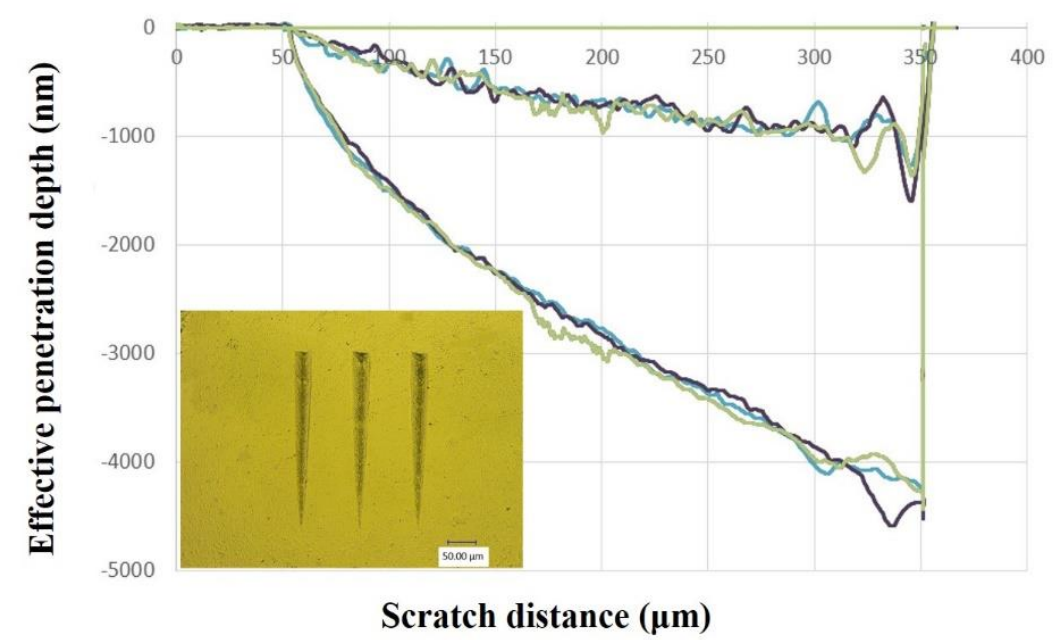

Figure 4. The effective penetration depth curves of neat dental resin matrix under load. 


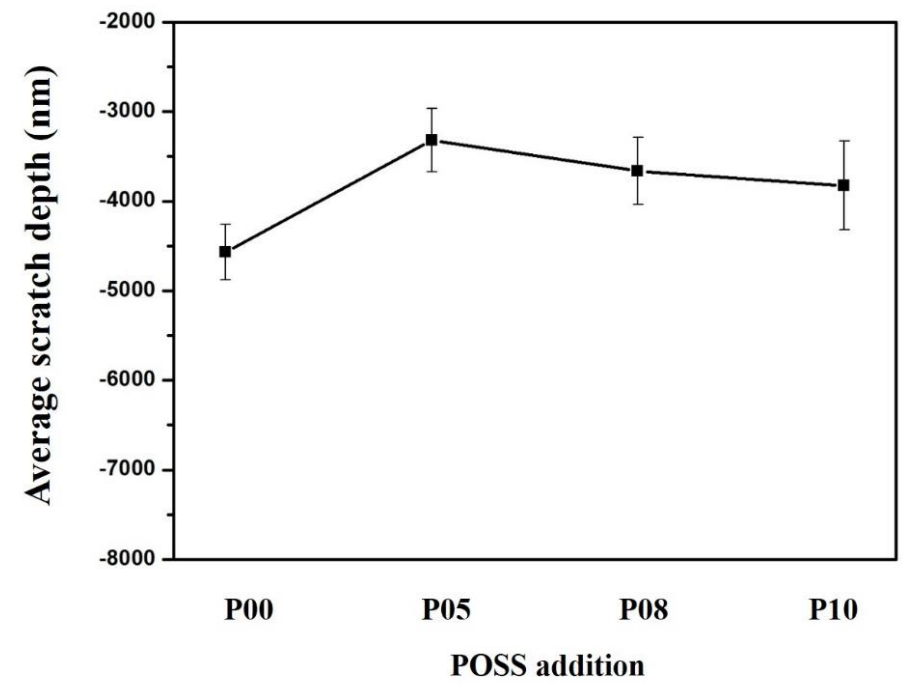

Figure 5. Average scratch depth of composite resins with different POSS additions.

Flexural strength and fracture energy can reflect the ability to withstand complex loads for dental restorations. The results of flexural strength and fracture energy of composite resins with different POSS additions were shown in Figure 6 and SEM images of the fracture topography of the organic dental composite resin and POSS hybrid dental composite resin were shown in Figure 7. When the addition of $2 \mathrm{wt} \%$, POSS increased the flexural strength and fracture energy. POSS monomers polymerized with the matrix to form a cross-linked net framework. POSS can be helpful to increase the toughness of resins. The formation of a cross-linked polymeric network with more POSS was obvious. The flexural strength and fracture energy of the POSS dental resin matrix decreased sharply. POSS has a unique microparticle surface structure, which is closely bonded to the resin matrix interface. The addition of a small amount can make the material have excellent mechanical properties compared with ordinary composite materials. Meanwhile, the interface layer formed between the modified nano $\mathrm{SiO}_{2}$ particles and the POSS organic-inorganic molecule has higher strength. Modification of nano $\mathrm{SiO}_{2}$ with a coupling agent can reduce particle agglomeration. As a result, the distribution of nano $\mathrm{SiO}_{2}$ is more uniform and the effect of reinforcing and toughening is also obvious.

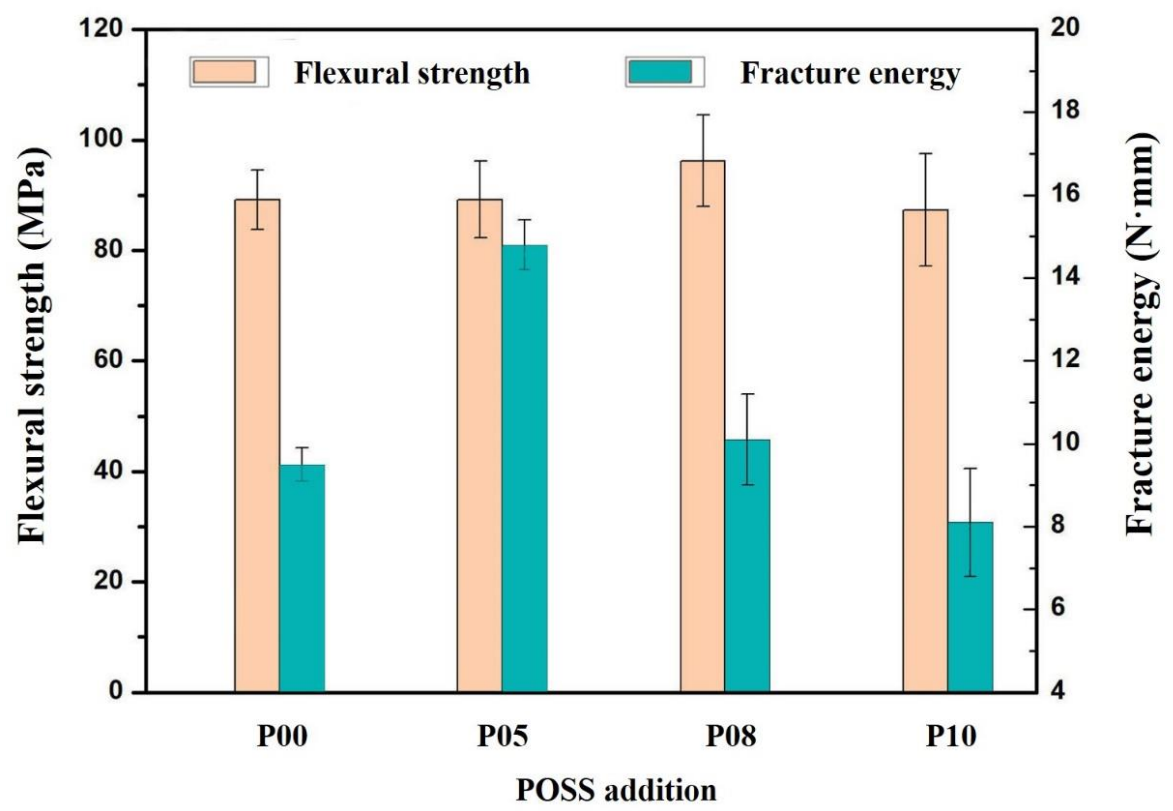

Figure 6. Flexural strength and fracture energy of composite resins with different POSS additions. 


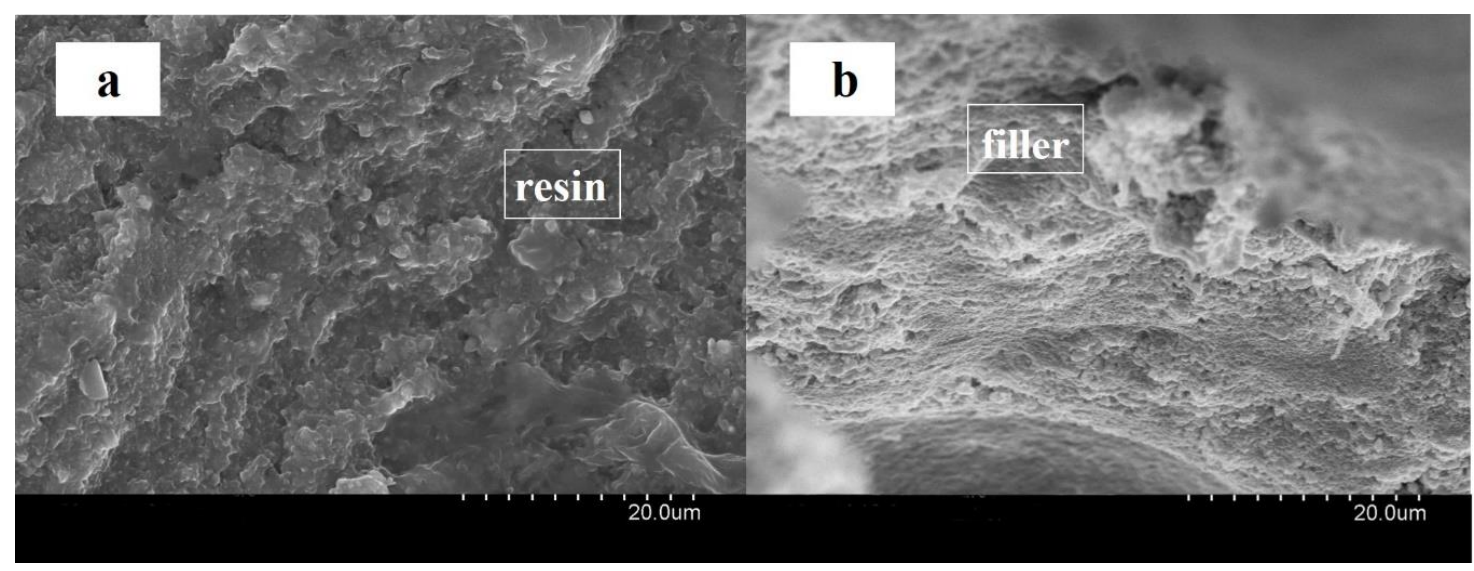

Figure 7. Scanning electron microscopy (SEM) images of the fracture topography of (a) organic dental composite resin and (b) POSS hybrid dental composite resin.

The POSS particles can increase the properties of the composite resin matrix. The big size effect of the particles can cause stress concentration under loading. The resin matrix around the organic and inorganic materials produces yielding phenomena including cavitation, shear zones and crazing. POSS particles can prevent cracks to a certain extent or terminate crack blunting and crack propagation. A lot of energy is consumed, and the craze damage further develops into cracks under the effect of stress. The mechanism of transition between cracks and cracking damage may be due to the structural defects of the polymer. When the polymer is affected by various external forces, stress concentration and cracking damage occurred [34-36]. If no nanoparticles are embedded in the resin material, the craze will gradually develop into the destructive crack which will lead to fracture of the material. However, with the enforcement of nanoparticles, they are able to enter the interior of the gap to form a filamentous connection structure. The filamentous connection delays the fracture of the resin material, so that more external energy is consumed for the material to fracture. The toughness and strength of the material are thus improved.

However, once the content of nanoparticles exceeds a certain limit, the internal gaps between cracks will be smaller than the diameter of the clumps. This results in the nanoparticles becoming unable enter the gap and the crack cannot return to the state of craze. The material produces a larger gap or deformation under the impact forces and even generates macroscopic cracks. Therefore, the nanoparticles tend to cause the impact strength and toughness of the resin material to decrease when the stress concentration occurs. In addition, the existence of particles prevents the crack from fracturing. Therefore, the addition of POSS fillers should be within a certain limit or it will have an adverse effect. Since the nano $\mathrm{SiO}_{2}$ and POSS in the composite resin are both nano-scale. They can be distributed uniformly and also expand the interface region between the matrix and the filler [37]. The resin and nanofiller interact at the interface and exhibit physical cross-linking or a nano effect, which transfers the stress and increases the mechanical properties.

Meanwhile, the mechanical properties of resin materials are closely related to its curing degree. The effect of curing is related to light intensity, time and color of the resin. The addition of inorganic filler will affect its light transmittance, which further reduces the curing effect. Meanwhile, the POSS composite resin is viscous. When it is injected into the mold, it may form tiny bubbles, which will cause a tiny void in the resin and decrease the mechanical properties of the resin.

\section{Conclusions}

In this work, various amounts of methacryl POSS were explored to be incorporated into novel nano $\mathrm{SiO}_{2}$ dental resin composites using light curing method. The volumetric shrinkage and mechanical properties such as hardness, elastic modulus, resistance, flexural strength and fracture energy were analyzed and the effects of POSS on these properties were studied. 
With the additions of POSS, the volume shrinkage decreased remarkably. The values were about $2.98 \%, 2.87 \%$ and $2.54 \%$ with the addition of $2 \%, 5 \%$ and $10 \%$ POSS, respectively. POSS reduced the shrinkage of resins obviously due to the limitation of free volume variation.

As for the mechanical properties, the POSS hybrid inorganic dental composite resin exhibited a positive reinforcement effect when a small amount of POSS was added. When it exceeded $5 \mathrm{wt} \%$, heterogeneous distribution and stress concentration appeared. The mechanical properties of the POSS composite resin reduced. The big size effect of the particles can cause stress concentration under loading. With the enforcement of nanoparticles, they were able to enter the interior of the gap and interface region to exhibit physical cross-linking or a nano effect, which transfers the stress and increases the mechanical properties.

Author Contributions: J.W. conceived and designed the experiments; Y.L., J.Y. and W.X. performed most of the experiments, analyzed the data and plotted the figures, Y.S. wrote the paper. All authors have read and agreed to the published version of the manuscript.

Funding: This research was funded by the National Natural Science Foundation of China (Grant No.11602073) and the Natural Science Foundation of Heilongjiang Province of China (Grant No. QC2018005). This research was also supported by the Fundamental Research Funds for the Central Universities (Grant No.HIT.NSRIF.201821)

Conflicts of Interest: The authors declare no conflict of interest. The funders had no role in the design of the study; in the collection, analyses, or interpretation of data; in the writing of the manuscript, or in the decision to publish the results.

\section{References}

1. Soares, L.M.; Razaghy, M.; Magne, P. Optimization of large MOD restorations: Composite resin inlays vs. short fiber-reinforced direct restorations. Dent. Mater. 2018, 34, 587-597. [CrossRef]

2. de Castro Kruly, P.; Giannini, M.; Pascotto, R.C.; Tokubo, L.M.; Suga, U.S.G.; Marques, A.D.C.R.; Terada, R.S.S. Meta-analysis of the clinical behavior of posterior direct resin restorations: Low polymerization shrinkage resin in comparison to methacrylate composite resin. PLoS ONE 2018, 13, e0191942.

3. Taha, N.; Maghaireh, G.; Ghannam, A.; Palamara, J. Effect of bulk-fill base material on fracture strength of root-filled teeth restored with laminate resin composite restorations. J. Dent. 2017, 63, 60-64. [CrossRef]

4. Yudovin-Farber, I.; Beyth, N.; Nyska, A.; Weiss, E.I.; Golenser, J.; Domb, A.J. Surface characterization and biocompatibility of restorative resin containing nanoparticles. Biomacromolecules 2008, 9, 3044-3055. [CrossRef] [PubMed]

5. Liu, Y.; Tan, Y.; Lei, T.; Xiang, Q.; Han, Y.; Huang, B. Effect of porous glass-ceramic fillers on mechanical properties of light-cured dental resin composites. Dent. Mater. 2009, 25, 709-715. [CrossRef] [PubMed]

6. Nikolaidis, A.K.; Koulaouzidou, E.A.; Gogos, C.; Achilias, D.S. Synthesis and Characterization of Dental Nanocomposite Resins Filled with Different Clay Nanoparticles. Polymers. 2019, 11, 730. [CrossRef]

7. Blanco, I. Polyhedral oligomeric silsesquioxanes (POSS) s in medicine. J. Nanomed. 2018, 1, 1002. [CrossRef]

8. Blanco, I. The rediscovery of POSS: A molecule rather than a filler. Polymers 2018, 10, 904. [CrossRef] [PubMed]

9. Mohamed, M.; Kuo, S. Functional polyimide/polyhedral oligomeric silsesquioxane nanocomposites. Polymers 2019, 11, 26. [CrossRef] [PubMed]

10. Zaharescu, T.; Blanco, I.; Bottino, F. Antioxidant activity assisted by modified particle surface in POSS/EPDM hybrids. Appl. Surf. Sci. 2019, 509, 144702. [CrossRef]

11. Blanco, I.; Bottino, F.; Abate, L. Influence of n-alkyl substituents on the thermal behaviour of Polyhedral Oligomeric Silsesquioxanes (POSSs) with different cage's periphery. Thermochim. Acta. 2016, 623, 50-57. [CrossRef]

12. Zhang, W.; Camino, G.; Yang, R. Polymer/polyhedral oligomeric silsesquioxane (POSS) nanocomposites: An overview of fire retardance. Prog. Polym. Sci. 2017, 67, 77-125. [CrossRef]

13. Gu, J.; Liang, C.; Dang, J.; Dong, W.; Zhang, Q. Ideal dielectric thermally conductive bismaleimide nanocomposites filled with polyhedral oligomeric silsesquioxane functionalized nanosized boron nitride. RSC Adv. 2016, 6, 35809-35814. [CrossRef] 
14. Huang, M.; Yue, K.; Huang, J.; Liu, C.; Zhou, Z.; Wang, J.; Wu, K.; Shan, W.; Shi, A.-C.; Cheng, S.Z.D. Highly Asymmetric Phase Behaviors of Polyhedral Oligomeric Silsesquioxane-Based Multiheaded Giant Surfactants. ACS Nano 2018, 12, 1868-1877. [CrossRef]

15. Ren, Z.; Nie, J.; Shao, J.; Lai, Q.; Wang, L.; Chen, J.; Chen, X.; Wang, Z.L. Fully Elastic and Metal-Free Tactile Sensors for Detecting both Normal and Tangential Forces Based on Triboelectric Nanogenerators. Adv. Funct. Mater. 2018, 28, 1802989. [CrossRef]

16. Zhang, R.; Gao, B.; Du, W.; Zhang, J.; Cui, H.; Liu, L.; Ma, Q.; Wang, C.; Li, F. Enhanced mechanical properties of multiscale carbon fiber/epoxy composites by fiber surface treatment with graphene oxide/polyhedral oligomeric silsesquioxane. Compos. Part A Appl. Sci. Manuf. 2016, 84, 455-463. [CrossRef]

17. Zhou, B.; Jiang, J.; Zhang, F.; Zhang, H. Crosslinked poly (ethylene oxide)-based membrane electrolyte consisting of polyhedral oligomeric silsesquioxane nanocages for all-solid-state lithium ion batteries. J. Power Sources 2020, 449, 227541. [CrossRef]

18. Yang, X.; Tang, L.; Guo, Y.; Liang, C.; Zhang, Q.; Kou, K.; Gu, J. Improvement of thermal conductivities for PPS dielectric nanocomposites via incorporating NH2-POSS functionalized nBN fillers. Compos. Part A Appl. Sci. Manuf. 2017, 101, 237-242. [CrossRef]

19. Deng, Y.-Y.; Han, D.; Zhou, D.-L.; Liu, Z.-Q.; Zhang, Q.; Li, Y.; Fu, Q. Monodispersed hybrid microparticles based on polyhedral oligomeric silsesquioxane with good UV resistance and high thermal stability: From organic to inorganic. Polymer 2019, 178, 121609. [CrossRef]

20. Carosio, F.; Alongi, J. Influence of layer by layer coatings containing octapropylammonium polyhedral oligomeric silsesquioxane and ammonium polyphosphate on the thermal stability and flammability of acrylic fabrics. J. Anal. Appl. Pyrolysis 2016, 119, 114-123. [CrossRef]

21. Fina, A.; Tabuani, D.; Carniato, F.; Frache, A.; Boccaleri, E.; Camino, G. Polyhedral oligomeric silsesquioxanes (POSS) thermal degradation. Thermochim. Acta 2006, 440, 36-42. [CrossRef]

22. Liu, Y.R.; Huang, Y.D.; Liu, L. Thermal stability of POSS/methylsilicone nanocomposites. Compos. Sci. Technol. 2007, 67, 2864-2876. [CrossRef]

23. Liu, Y.Z.; Sun, Y.; Zeng, F.L.; Zhang, Q.H.; Geng, L. Characterization and analysis on atomic oxygen resistance of POSS/PVDF composites. Appl. Surf. Sci. 2014, 320, 908-913. [CrossRef]

24. Siang Soh, M.; Sellinger, A.; Uj Yap, A. Dental nanocomposites. Curr. Nanosci. 2006, 2, 373-381. [CrossRef]

25. Canellas, T.A.T.; de Almeida Neves, A.; dos Santos, I.K.B.; de Rezende, A.R.P.; Fellows, C.E.; da Silva, E.M. Characterization of low-shrinkage dental composites containing methacrylethyl-polyhedral oligomeric silsesquioxane (ME-POSS). J. Mech. Behav. Biomed. Mater. 2019, 90, 566-574. [CrossRef] [PubMed]

26. Eick, J.D.; Smith, R.E.; Pinzino, C.S. Stability of silorane dental monomers in aqueous systems. J. Dent. 2006, 34, 405-410. [CrossRef] [PubMed]

27. Meereis, C.T.; Leal, F.B.; Ogliari, F.A. Stability of initiation systems in acidic photopolymerizable dental material. Dent. Mater. 2016, 32, 889-898. [CrossRef]

28. Kumar, S.R.; Bhat, I.; Patnaik, A. Novel dental composite material reinforced with silane functionalized microsized gypsum filler particles. Polym. Compos. 2017, 38, 404-415. [CrossRef]

29. Fong, H.; Dickens, S.H.; Flaim, G.M. Evaluation of dental restorative composites containing polyhedral oligomeric silsesquioxane methacrylate. Dent. Mater. 2005, 21, 520-529. [CrossRef]

30. Wu, X.; Sun, Y.; Xie, W.; Liu, Y.; Song, X. Development of novel dental nanocomposites reinforced with polyhedral oligomeric silsesquioxane (POSS). Dent. Mater. 2010, 26, 456-462. [CrossRef]

31. Liu, Y.; Wu, X.; Sun, Y.; Xie, W. POSS Dental Nanocomposite Resin: Synthesis, Shrinkage, Double Bond Conversion, Hardness, and Resistance Properties. Polymers 2018, 10, 369. [CrossRef] [PubMed]

32. Blanco, I.; Bottino, F.A.; Cicala, G.; Cozzo, G.; Latteri, A.; Recca, A. Synthesis and thermal characterization of new dumbbell shaped POSS/PS nanocomposites: Influence of the symmetrical structure of the nanoparticles on the dispersion/aggregation in the polymer matrix. Polym. Compos. 2015, 36, 1394-1400. [CrossRef]

33. Chun, K.J.; Lee, J.Y. Comparative study of mechanical properties of dental restorative materials and dental hard tissues in compressive loads. J. Dent. Biomech. 2014, 5, 1758736014555246. [CrossRef]

34. Wu, S. Chain structure, phase morphology, and toughness relationships in polymers and blends. Polym. Eng. Sci. 1990, 30, 753-761. [CrossRef]

35. Miller, P.; Kramer, E.J. Environmental shear deformation zones and crazes in crosslinked polystyrene and poly (para-methylstyrene). J. Mater. Sci. 1990, 25, 1751-1761. [CrossRef] 
36. Berger, E.J.K.L. Fundamental processes of craze growth and fracture. Crazing Polym. 1990, 2, 1-68.

37. Douce, J.; Boilot, J.P.; Biteau, J.; Scodellaro, L.; Jimenez, A. Effect of filler size and surface condition of nano-sized silica particles in polysiloxane coatings. Thin Solid Film. 2004, 466, 114-122. [CrossRef] 